\title{
Common ABCB1 polymorphisms associated with susceptibility to infantile spasms in the Chinese Han population
}

\author{
L. Dong ${ }^{1,2,3}$, M. Mao ${ }^{1,2,3}$, R. Luo ${ }^{1,2}$, Y. Tong ${ }^{2,3}$ and D. Yu ${ }^{1,2,3}$ \\ ${ }^{1}$ Department of Pediatrics, West China Second University Hospital, \\ Sichuan University, Chengdu, China \\ ${ }^{2}$ Laboratory of Early Developmental and Injuries, \\ West China Institute of Woman and Children's Health, \\ West China Second University Hospital, Sichuan University, Chengdu, China \\ ${ }^{3}$ Key Laboratory of Obstetric \& Gynecologic and Pediatric Diseases and Birth \\ Defects of Ministry of Education, China \\ Corresponding author: D. Yu \\ E-mail: yd540@126.com
}

Genet. Mol. Res. 10 (4): 2569-2577 (2011)

Received March 11, 2011

Accepted June 1, 2011

Published October 19, 2011

DOI http://dx.doi.org/10.4238/2001.October.19.3

\begin{abstract}
Infantile spasms are a severe epileptic encephalopathy with a variety of etiologies that occur in infancy and early childhood. Subjects with infantile spasms are at a higher risk for evolving into intractable epileptic spasms, tending to be refractory to conventional antiepileptic drugs. Genetic polymorphisms of the P-glycoprotein-encoding gene ABCB1 are suspected to be associated with pharmacoresistance phenotypes in epilepsy patients. Conflicting findings have been reported in different populations; few studies have explored whether this apparent association is affected by other host factors, such as specific epilepsy syndrome. We performed a case-control study to determine whether the risk of infantile spasms is influenced by common ABCB1 polymorphisms in a Han Chinese children's population consisting of 91 patients and 368 healthy individuals. DNA was isolated from whole blood, and three genetic polymorphisms (C1236T, G2677T/A,
\end{abstract}


and $\mathrm{C} 3435 \mathrm{~T}$ ) were assayed by PCR-RFLP. There were significant differences in the distributions of 3435TT $[\mathrm{P}=0.001$; odds ratio $=2.47$; $95 \%$ confidence interval $(\mathrm{CI})=1.44-4.27]$ and $3435 \mathrm{CT}[\mathrm{P}<0.001$; odds ratio $=0.28 ; 95 \% \mathrm{CI}=0.15-0.54]$ genotypes between infantile spasm cases and controls. No significant differences were observed in allelic and haplotypic frequencies of $\mathrm{ABCB} 1$ polymorphisms between the two groups. This study demonstrated that variations in the C3435T gene play an important role in the pathogenesis of infantile spasms in the Han Chinese population; $3435 \mathrm{TT}$ is associated with increased risk of having this epilepsy syndrome.

Key words: Infantile spasms; ABCB1 gene; Genetic polymorphisms

\section{INTRODUCTION}

Infantile spasms (West syndrome) constitute an epilepsy syndrome, which affects 1 in 2000 infants (Pellock, 1990; Mikati et al., 2002). This epileptic disorder of infancy or early childhood is characterized by the triad of infantile spasms, hypsarrhythmia, and cognitive deterioration (Lux and Osborne, 2004). Unfortunately, as a severe epileptic encephalopathy with heterogeneous etiology, treatments of infantile spasms are very limited and incompletely effective (Wheless et al., 2005, 2007; Tsuji et al., 2007). Due to the complex molecular pathogenesis of infantile spasms, patients with this epilepsy syndrome tend to have a higher risk of developing pharmacoresistant epilepsy, which is refractory to conventional antiepileptic drugs (AEDs; Koo et al., 1993; Riikonen, 2004; Frost Jr. and Hrachovy, 2005). There is still lack of consensus with regard to current trends in the treatment of infantile spasms. Two options are available at the moment: the first is ACTH or oral corticosteroids, the other is the use of vigabatin or other alternative anticonvulsant drugs (Bobele and Bodensteiner, 1994; Ito et al., 2000; Fois, 2010). The majority of AEDs, which are planar lipophilic agents and theoretical substrates for P-glycoprotein (P-gp) transporter, are not first choice or the gold standard for these patients (Hancock et al., 2001; Wheless et al., 2005, 2007; Willmore et al., 2009). One hypothesis for unsatisfactory drug response has been attributed to enhanced blood brain barrier expression of P-gp, which has been suggested to reduce the brain penetration of many AEDs (Tishler et al., 1995; Aronica et al., 2004; Leschziner et al., 2007). Overexpression of $\mathrm{P}$-gp could be a result of either prolonged or frequent seizures, which was demonstrated in rodent epilepsy models, or of genetic factors, such as polymorphisms of its coding gene ABCB1 or, theoretically, of both (Loscher and Delanty, 2009). Previous studies investigating the association between $\mathrm{ABCB} 1$ polymorphisms and drug response in epilepsy have been carried out in different ethnic backgrounds with conflicting results (Siddiqui et al., 2003; Zimprich et al., 2004; Seo et al., 2006; Kwan et al., 2007; Hung et al., 2007). However, few studies have explored the level of the participation of ABCB1 gene polymorphisms in relation to the risk of a special epilepsy syndrome (West syndrome) in a children's population, which essentially influences drug response as a host characteristic. In this study, we examined the C1236T, C3435T, and G2677T/A allelic and genotypic distributions in a case-control Han Chinese sample, and investigated the relationship between potentially functional variants in ABCB1 polymorphisms and risk of patients with infantile spasms. 


\section{MATERIAL AND METHODS}

\section{Subjects}

Patients in this case-control study were 91 unrelated Han Chinese children with infantile spasms, recruited from the Department of Pediatric Neurology, West China Second University Hospital in Chengdu. The diagnosis of this epileptic syndrome was carried out by the senior pediatric neurologists according to the guidelines of the International League Against Epilepsy (ILAE) (Engel Jr., 2001). An electroencephalogram (EEG) detected either classic or modified hypsarrhythmia. Infantile spasms have been classified as cryptogenic when a possible etiology is suspected but absent from the identified underlying cause, and symptomatic when the seizure arises from a definite cause, an apparent developmental delay prior to the onset of spasms, and abnormal CT or MRI findings of the head (Lux and Osborne, 2004; Frost Jr. and Hrachovy, 2005). Exclusion criteria were race other than Han and infantile spasms in association with other lethal disease or as a part of genetic syndrome. In addition, 368 unrelated healthy children were selected via health screening at the same hospital. All participants were of the same ethnic origin. Participants or their parents signed a written informed consent form, and this study was approved by the Institutional Ethics Committee of the West China Second University Hospital, Chengdu.

\section{Genotyping}

Genetic polymorphisms were assessed in DNA extracted from peripheral blood leukocytes using the "salting-out" procedure (Miller et al., 1988). PCR-RFLP protocols were described as below (Table 1). All the restriction enzymes used in this study were supplied by New England Biolabs (USA). Reproducibility of genotyping was assured by conducting duplicate experiments, and analysis of genotypes was determined blind to case-control status. Determination of genotypes was performed on $2.5 \%$ agarose gel, stained with ethidium bromide and visualized under UV light. PCR products of samples representative of different genotype of $\mathrm{ABCB} 1$ polymorphic loci were sequenced directly using the AB Sequence Detection System 7500 v 1.4 software package (Applied Biosystems) (Figure 1).

Table 1. PCR-RFLP assays for genotyping of ABCB1 polymorphisms.

\begin{tabular}{|c|c|c|c|c|}
\hline Gene & Primer sequence & Annealing temperature & Endonuclease & Cleavage products (bp) \\
\hline $\begin{array}{l}\mathrm{C} 1236 \mathrm{~T} \\
(\mathrm{rs} 1128503)\end{array}$ & $\begin{array}{l}\text { F: 5'-ATC CTG TGT CTG TGA ATT GC-3' } \\
\text { R: 5'-TCA GAA AGA TGT GCA ATG TG-3' }\end{array}$ & $59^{\circ} \mathrm{C}$ & EcoO109I & $\begin{array}{l}\text { CC: } 180+60 \\
\text { CT: } 240+180+60 \\
\text { TT: } 240\end{array}$ \\
\hline $\begin{array}{l}\mathrm{C} 3435 \mathrm{~T} \\
(\mathrm{rs} 1045642)\end{array}$ & $\begin{array}{l}\text { F: 5'-TGA TGG CAA AGA AAT AAA GCG A-3' } \\
\text { R: 5'-TGA CTC GAT GAA GGC ATG TAT GT-3' }\end{array}$ & $56^{\circ} \mathrm{C}$ & MboI & $\begin{array}{l}\text { CC: } 144+49 \\
\text { CT: } 193+144+49 \\
\text { TT: } 193\end{array}$ \\
\hline $\begin{array}{l}\text { G2677T } \\
(\mathrm{rs} 2032582)\end{array}$ & $\begin{array}{l}\text { F: 5'-TGC AGG CTA TAG GTT CCA GG-3' } \\
\text { R: 5'-TTT AGT TTG ACT CAC CTT CCC G-3' }\end{array}$ & $60^{\circ} \mathrm{C}$ & BanI & $\begin{array}{l}\text { GG: } 198+26 \\
\text { GT: } 224+198+26 \\
\text { TT: } 224\end{array}$ \\
\hline $\begin{array}{l}\text { G2677A } \\
(\mathrm{rs} 2032582)\end{array}$ & $\begin{array}{l}\text { F: 5'-TGC AGG CTA TAG GTT CCA GG-3' } \\
\text { R: 5'-GTT TGA CTC ACC TTC CCA G-3' }\end{array}$ & $60^{\circ} \mathrm{C}$ & $B s r \mathrm{I}$ & $\begin{array}{l}\text { GG: } 220 \\
\text { GA: } 220+206+14 \\
\text { AA: } 206+14\end{array}$ \\
\hline
\end{tabular}

$\mathrm{F}=$ forward sequence; $\mathrm{R}=$ reverse sequence. 

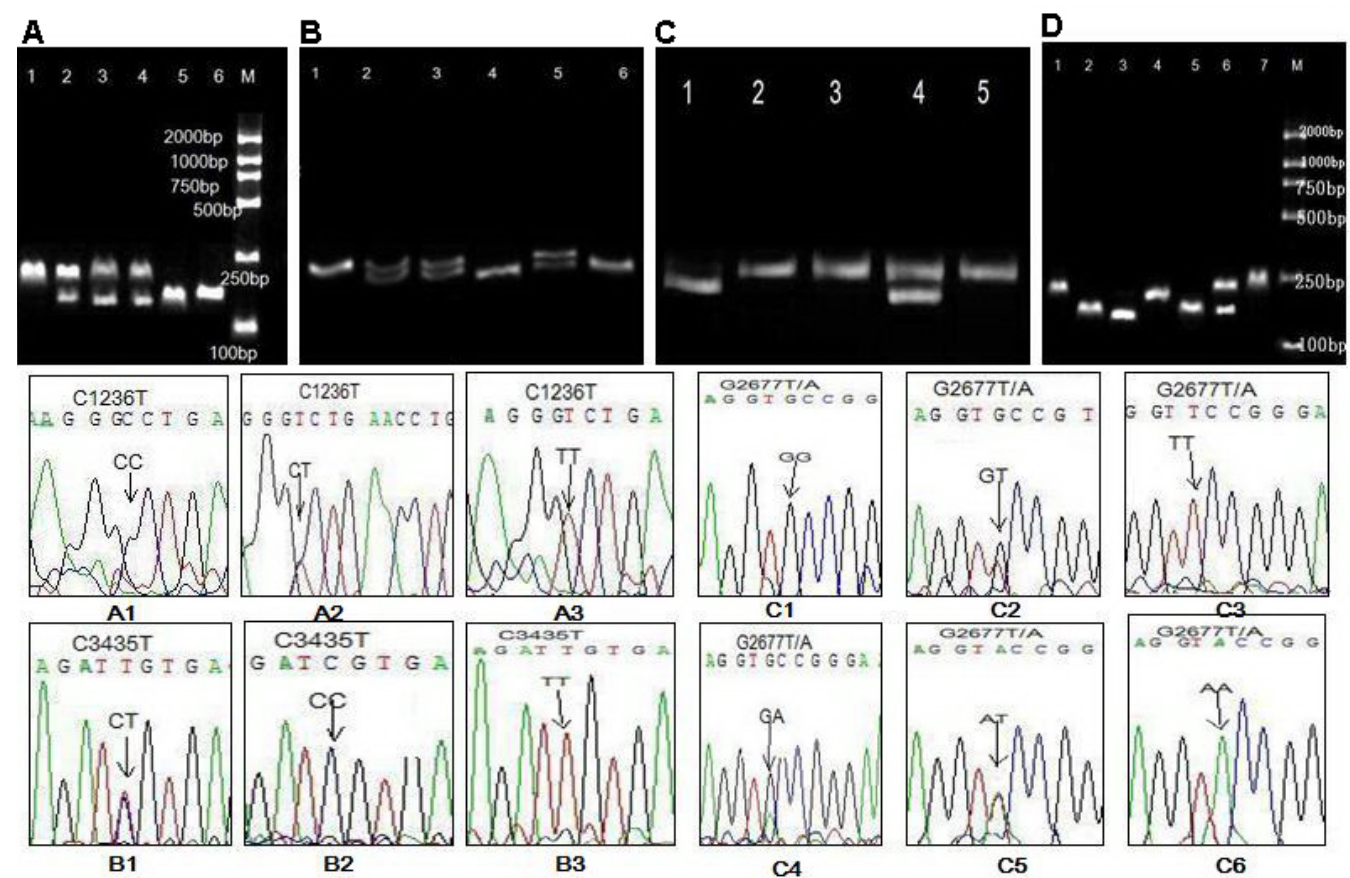

Figure 1. Determination of C1236T, G2677T/A and C3435T genotypes of ABCB1 polymorphisms by gel electrophoresis after PCR-RFLP and verified by DNA sequencing tests. A. PCR amplifications of locus C1236T digested by EcoO109I. $\mathrm{M}=$ Molecular marker; lanes 2, 3, $4=\mathrm{CT}$; lane $1=\mathrm{TT}$; lanes 5, $6=\mathrm{CC}$. B. PCR amplifications of locus G2677T digested by BanI. Lanes 2, 3, 5= GT; lane $1=\mathrm{TT}$; lanes 4, $6=\mathrm{GG}$. C. PCR amplifications of locus G2677A digested by BsrI. Lane 4= GA; lanes 2, 3, 5= GG; lane $1=\mathrm{AA}$. D. PCR amplifications of locus C3435T digested by MboI. $\mathrm{M}=$ Molecular marker; lane $6=\mathrm{CT}$; lanes 1, 4, 7= TT; lanes 2, 3, 5= CC. A1-A3, B1-B3 and C1-C6 = results of DNA sequencing of each genotype, and SNP positions indicated by arrows, respectively.

\section{Statistical analysis}

Frequencies of the alleles and genotypes were calculated by counting. The assumption of the Hardy-Weinberg equilibrium was tested by means of the chi-square test. Comparison between case-control groups was performed using contingency tables analyzed by the chisquare test or the Fisher exact test. Further analysis of linkage disequilibrium and haplotype effects of the three SNPs in the ABCB1 gene were performed using the Haploview program, version 4.2 (http://www.broad.mit.edu/mpg/haploview). SPSS version 13.0 was used to estimate odds ratios (OR) and confidence intervals (CI) at the 95\% significance level. P $<0.05$ was considered to be statistically significant.

\section{RESULTS}

\section{Baseline characteristics of the study population}

Demographic and clinical characteristics of infantile spasms and control subjects are 
shown in Table 2. A total of 459 individuals (91 infantile spasms patients and 368 controls) were analyzed for C1236T, G2677T/A and C3435T polymorphisms. The proportion of males was $69 \%$ in cases and $32 \%$ in controls. Mean age ( \pm standard deviation, SD) was $1.07 \pm 0.87$ years among cases and $6.12 \pm 3.53$ years among controls. Of the patient group, the ratio of cryptogenic to symptomatic spasms was $38: 53$ and the mean age at onset $( \pm \mathrm{SD})$ was $0.54 \pm$ 0.39 years.

Table 2. Characteristics of the study population.
\begin{tabular}{lcc} 
& \\
\hline & Infantile spasm patients & Controls \\
\hline Age (years) (means \pm SD) & $1.07 \pm 0.87$ & $6.12 \pm 3.53$ \\
Gender (male:female) & $63: 28$ & $119: 249$ \\
Age at onset (years) (means \pm SD) & $0.54 \pm 0.39$ & - \\
Etiology & 53 & - \\
Symptomatic & 38 & - \\
Cryptogenic & & - \\
\hline
\end{tabular}

\section{Genotype frequencies of $\mathrm{ABCB} 1 \mathrm{SNPs}$ between cases and controls}

The distributions of genotype frequencies of $\mathrm{ABCB} 1$ polymorphisms in infantile spasm children and healthy individuals are shown in Table 3. Genotype frequencies of the three SNPs were all compatible with Hardy-Weinberg equilibrium (HWE) in both groups (for the patient group, $\mathrm{P}=0.75,0.25$ and 0.57 for C1236T, G2677T/A and C3435T, and for the control group, $\mathrm{P}=0.65,0.26$ and 0.75 , respectively). The percentages of observed frequencies for CC, CT, TT genotypes of C3435T were $41.8,15.4$ and $42.8 \%$ for infantile spasm cases and $36.7,48.1$ and $15.2 \%$ for controls, respectively. The genotype frequencies of ABCB1 C3435T differed significantly between infantile spasm cases and controls with respect to the 3435TT $[\mathrm{P}=0.001, \mathrm{OR}=2.47,95 \% \mathrm{CI}=1.44-4.27]$ and $\mathrm{CT}[\mathrm{P}<0.001, \mathrm{OR}=0.28,95 \% \mathrm{CI}=0.15$ $0.54]$ genotypes. The frequency of ABCB1 C1236T and G2677T/A genotypes did not differ significantly between infantile spasm cases and controls.

Table 3. Genotype frequencies of common SNPs in the ABCB1 gene in infantile spasm patients and in healthy controls.

\begin{tabular}{|c|c|c|c|c|c|}
\hline SNP & Case N (\%) & Control N (\%) & OR & $95 \% \mathrm{CI}$ & $P$ value \\
\hline \multicolumn{6}{|l|}{$\mathrm{C} 1236 \mathrm{~T}$} \\
\hline $\mathrm{C} / \mathrm{C}$ & $12(13.2)$ & $53(14.4)$ & - & - & - \\
\hline $\mathrm{C} / \mathrm{T}$ & $44(48.3)$ & $174(47.3)$ & 1.12 & $0.55-2.69$ & 0.76 \\
\hline $\mathrm{T} / \mathrm{T}$ & $35(38.5)$ & $141(38.3)$ & 1.10 & $0.53-2.27$ & 0.80 \\
\hline $\mathrm{C} / \mathrm{T}+\mathrm{T} / \mathrm{T}$ & $79(86.8)$ & $315(85.6)$ & 1.11 & $0.57-2.17$ & 0.77 \\
\hline \multicolumn{6}{|l|}{$\mathrm{C} 3435 \mathrm{~T}$} \\
\hline $\mathrm{C} / \mathrm{C}$ & $38(41.8)$ & $135(36.7)$ & - & - & - \\
\hline $\mathrm{C} / \mathrm{T}$ & $14(15.4)$ & $177(48.1)$ & 0.28 & $0.15-0.54$ & $<0.001$ \\
\hline $\mathrm{T} / \mathrm{T}$ & $39(42.8)$ & $56(15.2)$ & 2.47 & $1.44-4.27$ & 0.001 \\
\hline $\mathrm{C} / \mathrm{T}+\mathrm{T} / \mathrm{T}$ & $53(58.2)$ & $233(63.3)$ & 0.81 & $0.51-1.29$ & 0.37 \\
\hline \multicolumn{6}{|l|}{$\mathrm{G} 2677 \mathrm{~T} / \mathrm{A}$} \\
\hline $\mathrm{G} / \mathrm{G}$ & $18(19.8)$ & $75(20.4)$ & - & - & - \\
\hline $\mathrm{G} / \mathrm{T}$ or $\mathrm{A}$ & $44(48.3)$ & $204(55.4)$ & 0.90 & $0.49-1.65$ & 0.73 \\
\hline $\mathrm{T} / \mathrm{T}$ or $\mathrm{A}$ & $29(31.9)$ & $89(24.2)$ & 1.36 & $0.70-2.64$ & 0.37 \\
\hline $\mathrm{G} / \mathrm{T}$ or $\mathrm{A}+\mathrm{T} / \mathrm{T}$ or $\mathrm{A}$ & $73(80.2)$ & $293(79.6)$ & 1.04 & $0.58-1.84$ & 0.90 \\
\hline
\end{tabular}

$\mathrm{OR}=$ odds ratio $; \mathrm{CI}=$ confidence interval. 


\section{Allele frequencies of $\mathrm{ABCB} 1 \mathrm{SNPs}$ between cases and controls}

Table 4 indicates the C1236T, G2677T/A and C3435T allele frequencies for infantile spasm patients and controls. The frequency of ABCB1 C1236T, G2677T/A and C3435T alleles did not differ significantly between infantile spasm and control groups despite a minor overrepresentation of the $3435 \mathrm{C}$ variant allele carriers in the group of infantile spasm patients $(\mathrm{P}>0.05)$.

Table 4. Allele frequencies of common SNPs in the ABCB1 gene in infantile spasm patients and in healthy controls.

\begin{tabular}{lccccc}
\hline SNP & Case N (\%) & Control N (\%) & OR & $95 \%$ CI & P value \\
\hline C1236T & & & & & - \\
C & $68(37.4)$ & $280(38.0)$ & Reference & - & $0.74-1.44$ \\
T & $114(62.6)$ & $456(62.0)$ & 1.03 & - & 0.87 \\
C3435T & $115(63.2)$ & $447(60.7)$ & Reference & $0.64-1.26$ & - \\
C & $67(36.8)$ & $289(39.3)$ & 0.90 & - & 0.54 \\
T & $80(44.0)$ & $350(47.6)$ & Reference & $0.83-1.60$ & - \\
G2677T/A & $102(56.0)$ & $386(52.4)$ & 1.16 & 0.38 \\
G & & & & \\
T/A & & &
\end{tabular}

$\mathrm{OR}=$ odds ratio; $\mathrm{CI}=$ confidence interval.

\section{Distributions of haplotypes in $\mathrm{ABCB} 1$ gene between patients and controls.}

The locus C1236T (synonymous) was observed to be in strong LD with C3435T (synonymous) in both infantile spasm and control groups ( $\mathrm{D}^{\prime}=0.72$ and $\mathrm{D}^{\prime}=0.73$, respectively; Figure 2), indicating the importance of a possible effect of haplotypes from ABCB1 for determining phenotypes. In this study, the G2677T/A locus was the only one leading to non-
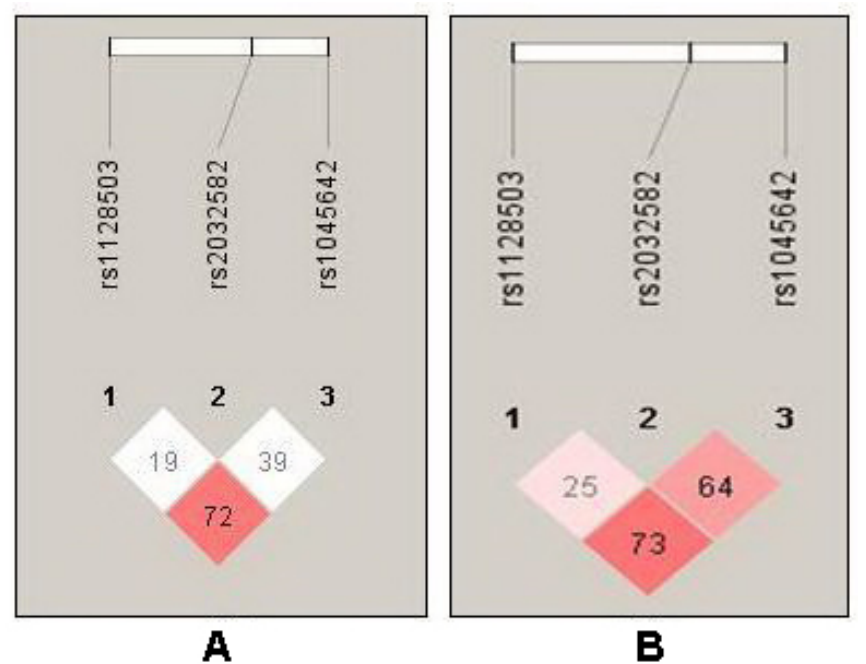

Figure 2. Output of linkage disequilibrium (LD) plot performed by using the Haploview program version 4.2. Each square represents a pairwise LD relationship between two SNPs with D'values for loci C1236T-G2677T/AC3435T, and C1236T-C3435T written in the box, respectively. A. The LD pattern in infantile spam patients. B. The LD pattern in healthy individuals. 
synonymous mutation, with $2677 \mathrm{G}$ coding for $893 \mathrm{Ala}$, $2677 \mathrm{~T}$ coding for $893 \mathrm{Ser}$, and $2677 \mathrm{~A}$ coding for $893 \mathrm{Thr}$. The least common of the three alleles, A, was counted as T to simplify the analysis. The frequencies of three-marker haplotypes are presented in Table 5. A total of 8 possible haplotypes were observed in both groups, with T-T/A-T $(28.8 \%)$ and T-G-C (18.5\%) being the most predominant haplotypes in the infantile spasm group. The frequencies of each combination of $\mathrm{ABCB} 1$ haplotypes did not show a significant difference between infantile spasm and control groups using the reference haplotype (CGC) $(\mathrm{P}>0.05)$.

\begin{tabular}{|c|c|c|c|c|c|c|}
\hline \multicolumn{3}{|c|}{ SNP } & \multicolumn{2}{|c|}{ Haplotype frequency } & \multirow[t]{2}{*}{ OR $(95 \% \mathrm{CI})$} & \multirow[t]{2}{*}{$P$ value } \\
\hline $\mathrm{C} 1236 \mathrm{~T}$ & $\mathrm{G} 2677 \mathrm{~T} / \mathrm{A}$ & C3435T & Case N (\%) & Control N (\%) & & \\
\hline $\mathrm{C}$ & G & $\mathrm{C}$ & $31(16.9)$ & $158(21.5)$ & Reference & - \\
\hline $\mathrm{T}$ & G & $\mathrm{C}$ & $34(18.5)$ & $144(19.5)$ & $1.20(0.70-2.06)$ & 0.50 \\
\hline $\mathrm{T}$ & G & $\mathrm{T}$ & $10(5.3)$ & $32(4.4)$ & $1.59(0.71-3.57)$ & 0.26 \\
\hline $\mathrm{C}$ & G & $\mathrm{T}$ & $6(3.2)$ & $16(2.2)$ & $1.91(0.69-5.27)$ & 0.23 \\
\hline $\mathrm{C}$ & $\mathrm{T} / \mathrm{A}$ & $\mathrm{C}$ & $30(16.6)$ & $94(12.8)$ & $1.63(0.93-2.86)$ & 0.09 \\
\hline $\mathrm{T}$ & $\mathrm{T} / \mathrm{A}$ & $\mathrm{T}$ & $52(28.8)$ & $229(31.1)$ & $1.16(0.71-1.89)$ & 0.56 \\
\hline $\mathrm{T}$ & $\mathrm{T} / \mathrm{A}$ & $\mathrm{C}$ & $19(10.7)$ & $52(7.0)$ & $1.86(0.97-3.57)$ & 0.06 \\
\hline C & $\mathrm{T} / \mathrm{A}$ & $\mathrm{T}$ & $0(0)^{*}$ & $11(1.5)$ & - & - \\
\hline
\end{tabular}

\section{DISCUSSION}

Results of the present study suggest that the 3435TT genotype of ABCB1 gene may be associated with susceptibility to infantile spasms in a Chinese Han children's population $(\mathrm{P}=$ $0.001, \mathrm{OR}=2.47,95 \% \mathrm{CI}=1.44-4.27)$. However, neither the $\mathrm{C}$ allele nor the $\mathrm{T}$ allele carriers of ABCB1 C3435T polymorphisms confer significant risk of infantile spasms. The predicted haplotype frequencies of the three loci did not reveal a significant difference between infantile spasm patients and controls. This is a novel finding because ABCB1 gene polymorphisms have not been previously studied for their association with the risk of infantile spasms, which is a special epilepsy syndrome in childhood, and further studies with larger sample size in different ethnic backgrounds are needed to confirm the association. An initial study reported by Siddiqui et al. (2003) has shown that the $3435 \mathrm{CC}$ genotype may play a role in the development of drug-resistant epilepsy; however, in two subsequent studies in Japanese and Chinese (Hong Kong) populations, the association was in the opposite direction (Seo et al., 2006; Kwan et al., 2007). Compared to studies in Caucasians, patients with pharmacoresistant epilepsy were more likely to have the TT genotype in the C3435T polymorphism in the Asian population, which highlights the complexity of the possible role of this SNP in antiepileptic drug response in different ethnic populations. The functional consequence of this SNP is still unclear. Kimchi-Safarty et al. (2007) have shown that C3435T in exon 26, a synonymous SNP, which does not produce a change in amino acid, is not essentially silent and gives rise to P-gp with modified drug and inhibitor interactions. It is also suggested that C3435T variations may alter P-gp function by affecting insertion and the time required for cotranslational folding of the protein (Komar, 2007).The results lead to the speculation that some rare synonymous SNPs may affect the synthesis of protein with the same amino acid but various structural or functional properties.

Of all infantile spasm children, 20 to $50 \%$ eventually develop Lennox-Gastaut syn- 
drome, which is considered to involve intractable epileptic spasms and may be very difficult to treat (Rantala and Putkonen, 1999; Wong and Trevathan, 2001). Prognosis for most patients with infantile spasms remains poor. Of the patients with symptomatic etiology, 80 to $95 \%$ have mental retardation, compared with $30-50 \%$ for patients with cryptogenic infantile spasms (Riikonen, 2004; Tsao, 2009). Subgroup analyses of epilepsy syndrome have not been described in reports of most previous similar studies, which tend to include all epilepsy patients as a single cohort, with the finding of a negative association between drug responsiveness and C3435T polymorphisms (Kim et al., 2006; Vahab et al., 2009). The main aim of our study was to identify the pattern of ABCB1 genetic markers in children with infantile spasms. Perhaps this would help us to understand why individuals with infantile spasms are more inclined to antiepileptic resistance on the basis of their genetic profile and further aid in investigating the potential pathogenesis of this epilepsy syndrome. We postulated that the interaction between $\mathrm{ABCB} 1$ polymorphisms and pharmacoresistant epilepsy may, at least on a theoretical level, involves regulation by epilepsy syndrome. However, at present, small sample size limits our ability to stratify the patient population on the basis of other variables including gender, medication regimen, etiology, and so on. It is our future plan to evaluate combined effects of other risk factors, including other candidate genes responsible for AED resistance and environmental exposure, conducted in cooperation with a number of research groups, which will produce prospective studies that will provide further clues for the understanding of genetic and environmental determinants of infantile spasms.

In conclusion, our results demonstrate that the 3435TT genotype is strongly associated with the risk of developing infantile spasms. The findings necessitate further studies for confirmation.

\section{ACKNOWLEDGMENTS}

Research supported by the National Natural Science Foundation of China (grants \#30700908, \#30772343, and \#30973215), and Program of Changjiang Scholars and Innovative Research Team in University, IRT0935. The authors thank all the staff and technicians who helped recruit the patients and collect blood samples for this study.

\section{REFERENCES}

Aronica E, Gorter JA, Ramkema M, Redeker S, et al. (2004). Expression and cellular distribution of multidrug resistancerelated proteins in the hippocampus of patients with mesial temporal lobe epilepsy. Epilepsia 45: 441-451.

Bobele GB and Bodensteiner JB (1994). The treatment of infantile spasms by child neurologists. J. Child. Neurol. 9: $432-435$.

Engel J Jr (2001). A proposed diagnostic scheme for people with epileptic seizures and with epilepsy: report of the ILAE Task Force on Classification and Terminology. Epilepsia 42: 796-803.

Fois A (2010). Infantile spasms: review of the literature and personal experience. Ital. J. Pediatr. 36: 15.

Frost JD Jr and Hrachovy RA (2005). Pathogenesis of infantile spasms: a model based on developmental desynchronization. J. Clin. Neurophysiol. 22: 25-36.

Hancock E, Osborne JP and Milner P (2001). The treatment of West syndrome: a Cochrane review of the literature to December 2000. Brain Dev. 23: 624-634.

Hung CC, Jen TJ, Kao PJ, Lin MS, et al. (2007). Association of polymorphisms in NR1I2 and ABCB1 genes with epilepsy treatment responses. Pharmacogenomics 8: 1151-1158.

Ito M, Seki T and Takuma Y (2000). Current therapy for West syndrome in Japan. J. Child. Neurol. 15: 424-428.

Kim YO, Kim MK, Woo YJ, Lee MC, et al. (2006). Single nucleotide polymorphisms in the multidrug resistance 1 gene 
in Korean epileptics. Seizure 15: 67-72.

Kimchi-Sarfaty C, Oh JM, Kim IW, Sauna ZE, et al. (2007). A "silent" polymorphism in the MDR1 gene changes substrate specificity. Science 315: 525-528.

Komar AA (2007). Silent SNPs: impact on gene function and phenotype. Pharmacogenomics 8: 1075-1080.

Koo B, Hwang PA and Logan WJ (1993). Infantile spasms: outcome and prognostic factors of cryptogenic and symptomatic groups. Neurology 43: 2322-2327.

Kwan P, Baum L, Wong V, Ng PW, et al. (2007). Association between ABCB1 C3435T polymorphism and drug-resistant epilepsy in Han Chinese. Epilepsy Behav. 11: 112-117.

Leschziner GD, Andrew T, Pirmohamed M and Johnson MR (2007). ABCB1 genotype and PGP expression, function and therapeutic drug response: a critical review and recommendations for future research. Pharmacogenomics $J$. 7: 154-179.

Loscher W and Delanty N (2009). MDR1/ABCB1 polymorphisms and multidrug resistance in epilepsy: in and out of fashion. Pharmacogenomics 10: 711-713.

Lux AL and Osborne JP (2004). A proposal for case definitions and outcome measures in studies of infantile spasms and West syndrome: consensus statement of the West Delphi group. Epilepsia 45: 1416-1428.

Mikati MA, Lepejian GA and Holmes GL (2002). Medical treatment of patients with infantile spasms. Clin. Neuropharmacol. 25: 61-70.

Miller SA, Dykes DD and Polesky HF (1988). A simple salting out procedure for extracting DNA from human nucleated cells. Nucleic Acids Res. 16: 1215.

Pellock JM (1990). The classification of childhood seizures and epilepsy syndromes. Neurol. Clin. 8: 619-632.

Rantala H and Putkonen T (1999). Occurrence, outcome, and prognostic factors of infantile spasms and Lennox-Gastaut syndrome. Epilepsia 40: 286-289.

Riikonen R (2004). Infantile spasms: therapy and outcome. J. Child. Neurol. 19: 401-404.

Seo T, Ishitsu T, Ueda N, Nakada N, et al. (2006). ABCB1 polymorphisms influence the response to antiepileptic drugs in Japanese epilepsy patients. Pharmacogenomics 7: 551-561.

Siddiqui A, Kerb R, Weale ME, Brinkmann U, et al. (2003). Association of multidrug resistance in epilepsy with a polymorphism in the drug-transporter gene ABCB1. N. Engl. J. Med. 348: 1442-1448.

Tishler DM, Weinberg KI, Hinton DR, Barbaro N, et al. (1995). MDR1 gene expression in brain of patients with medically intractable epilepsy. Epilepsia 36: 1-6.

Tsao CY (2009). Current trends in the treatment of infantile spasms. Neuropsychiatr. Dis. Treat. 5: 289-299.

Tsuji T, Okumura A, Ozawa H, Ito M, et al. (2007). Current treatment of West syndrome in Japan. J. Child Neurol. 22: 560-564.

Vahab SA, Sen S, Ravindran N, Mony S, et al. (2009). Analysis of genotype and haplotype effects of ABCB1 (MDR1) polymorphisms in the risk of medically refractory epilepsy in an Indian population. Drug. Metab. Pharmacokinet. 24: $255-260$.

Wheless JW, Clarke DF and Carpenter D (2005). Treatment of pediatric epilepsy: expert opinion, 2005. J. Child Neurol. 20 (Suppl 1): S1-56.

Wheless JW, Clarke DF, Arzimanoglou A and Carpenter D (2007). Treatment of pediatric epilepsy: European expert opinion, 2007. Epileptic Disord. 9: 353-412.

Willmore LJ, Abelson MB, Ben-Menachem E, Pellock JM, et al. (2009). Vigabatrin: 2008 update. Epilepsia 50: 163-173. Wong M and Trevathan E (2001). Infantile spasms. Pediatr. Neurol. 24: 89-98.

Zimprich F, Sunder-Plassmann R, Stogmann E and Gleiss A (2004). Association of an ABCB1 gene haplotype with phamacoresistance in temporal lobe epilepsy. Neurology. 63: 1087-1089. 